\title{
Design of Molecularly Ordered Framework of Mesoporous Silica with Squared One-Dimensional Channels
}

Tatsuo Kimura ${ }^{\dagger}$, Hiroaki Tamura ${ }^{\ddagger}$, Masato Tezuka ${ }^{\ddagger}$, Dai Mochizuki ${ }^{\ddagger}$, Tetsuro Shigeno ${ }^{\ddagger}$, Tetsu Ohsuna ${ }^{\S, \mathbb{I l}}$, Kazuyuki Kuroda ${ }^{\ddagger}, \S, \mathbb{I} *$

$\dagger$ Advanced Manufacturing Research Institute, National Institute of Advanced Industrial Science and Technology (AIST), Shimoshidami, Moriyama-ku, Nagoya 463-8560, Japan.

†Department of Applied Chemistry, Waseda University, Ohkubo 3-4-1, Shinjuku-ku, Tokyo 169-8555, Japan.

$\S$ Kagami Memorial Laboratory for Materials Science and Technology, Waseda University, Nishiwaseda 2-8-26, Shinjuku-ku, Tokyo 169-0051, Japan.

II Core Research for Evolutional Science and Technology (CREST), Japan Science and Technology Agency (JST), Kawaguchi-shi, Saitama 332-0012, Japan.

\section{Supporting Information}

\section{S1. Characterization of octoxytrichlorosilane.}

The ${ }^{29} \mathrm{Si}$ NMR spectrum of the separated solution exhibited a single peak at $-38.5 \mathrm{ppm}$ assignable to $\mathrm{Si}$ atom in $\mathrm{C}_{8} \mathrm{H}_{17} \mathrm{OSiCl}_{3}$ (Liepins, E.; Zicmane, I.; Lukevics, E. $J$. Organomet. Chem. 1986, 306, 167.). The ${ }^{13} \mathrm{C}$ NMR spectrum showed the presence of only peaks due to carbon atoms of octoxy group $\left(\mathrm{CH}_{3}\left(\mathrm{CH}_{2}\right)_{6} \mathrm{CH}_{2} \mathrm{OSiCl}_{3}\right)$. A peak due to $\alpha$ carbon in the group attached to $\mathrm{Si}$ atom appeared at $66.6 \mathrm{ppm}$ whereas a peak due to that in octyl alcohol $\left(\mathrm{CH}_{3}\left(\mathrm{CH}_{2}\right)_{6} \mathrm{CH}_{2} \mathrm{OH}\right)$ was not observed at around $62.5 \mathrm{ppm}$.
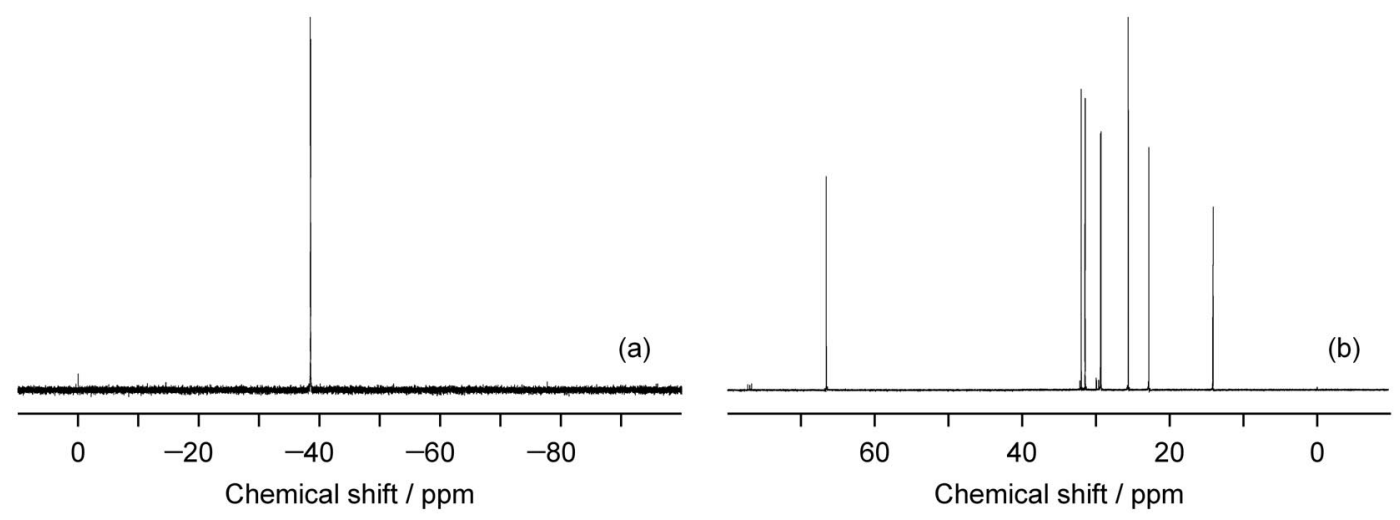

Figure S1. (a) ${ }^{29} \mathrm{Si} \mathrm{NMR}$ and (b) ${ }^{13} \mathrm{C} \mathrm{NMR}$ spectra of $\mathrm{C}_{8} \mathrm{H}_{17} \mathrm{OSiCl}_{3}$ after distillation. 


\section{S2. Characterization of kanemite.}

All of the XRD peaks can be indexed as characteristic peaks due to kanemite. On the basis of the reported kanemite structure (orthorhombic, No. 60 Pbcn), (Gies, H.; Marler, B.; Vortmann, S.; Oberhagemann, U.; Bayat, P.; Krink, K.; Rius, J.; Wolf, I.; Fyfe, C. Microporous Mesoporous Mater. 1998, 21, 183 ; Vortmann, S.; Rius, J.; Marler, B.; Gies, H. Eur. J. Mineral. 1999, 11, 125; Garvie, L. A. J.; Devouard, B.; Groy, T. L.; Camara, F.; Buseck, P. R. Am. Mineral. 1999, 84, 1170.) the $d$ values for the $(h k l)$ peaks are calculated, being in good agreement with the observed ones.
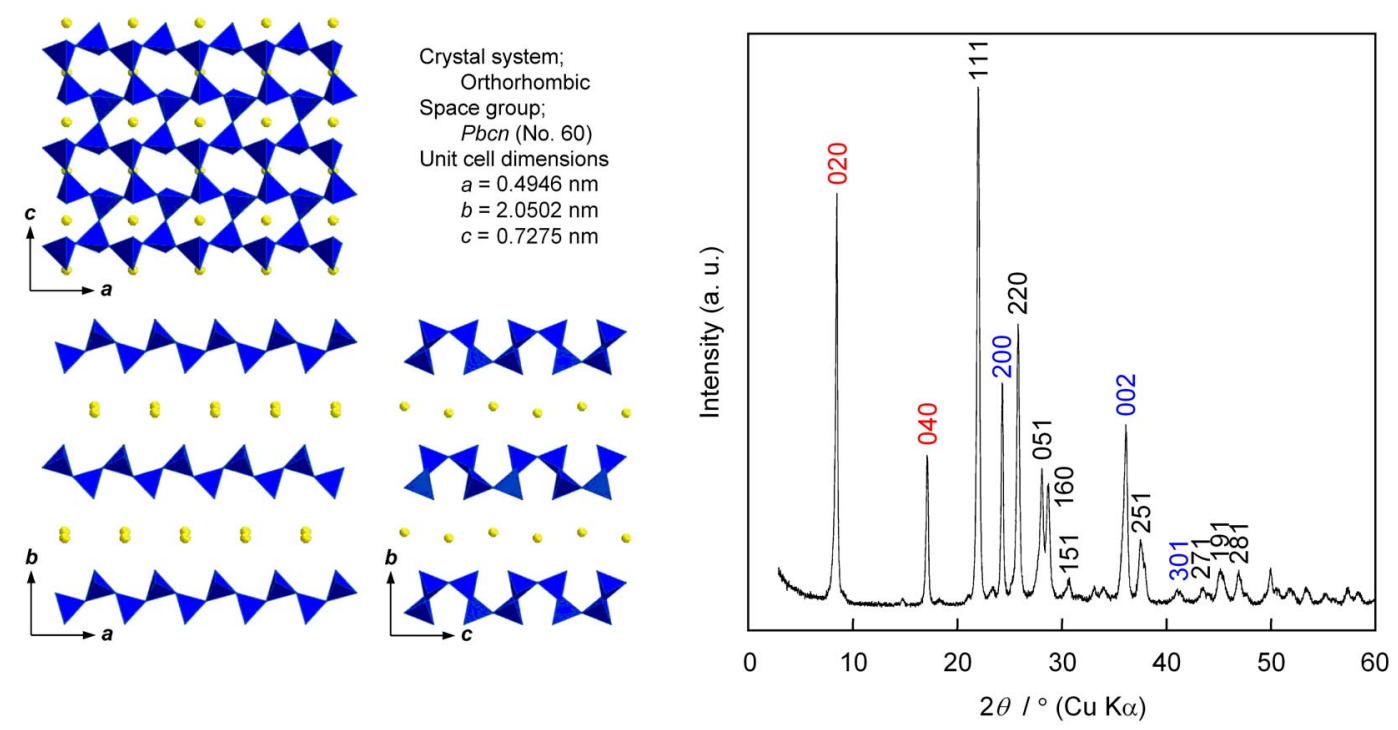

Figure S2. Crystal structure and XRD pattern of synthesized kanemite.

Table S1. XRD result on the synthesis of kanemite.

\begin{tabular}{lll}
\hline Observed & $h k l$ & $\begin{array}{l}\text { Calculated* (orthorhombic) } \\
a=0.4946 \mathrm{~nm} \\
b=2.0502 \mathrm{~nm} \\
c=0.7275 \mathrm{~nm}\end{array}$ \\
& & 1.0251 \\
1.027 & 020 & 0.5126 \\
0.515 & 040 & 0.4011 \\
0.402 & 111 & 0.3638 \\
0.365 & 002 & 0.3428 \\
0.344 & 022 & 0.3157 \\
0.316 & 150 & 0.3093 \\
0.310 & 061 & 0.2896 \\
0.290 & 151 & 0.2473 \\
0.248 & 200 & 0.2384 \\
0.239 & 152 & 0.2177 \\
0.219 & 103 &
\end{tabular}




\section{S3. Characterization of layered $\mathrm{C}_{16} \mathrm{TMA}$-kanemite complex and as-synthesized KSW-2.}

In our previous papers on the synthesis of layered $\mathrm{C}_{16}$ TMA-kanemite complex (Kimura, T.; Itoh, D.; Okazaki, N.; Kaneda, M.; Sakamoto, Y.; Terasaki, O.; Sugahara, Y.; Kuroda, K. Langmuir 2000, 16, 7624.) and as-synthesized KSW-2 (Kimura, T.; Kamata, T.; Fuziwara, M.; Takano, Y.; Kaneda, M.; Sakamoto, Y.; Terasaki, O.; Sugahara, Y.; Kuroda, K. Angew. Chem., Int. Ed. 2000, 39, 3855.), we described the possibility to retain the structural units originating from kanemite but the crystal structure has not been defined yet. All of the structural units disappear during calcination of the as-synthesized product to remove $\mathrm{C}_{16}$ TMA ions. Here, we have succeeded in retaining the structural units of kanemite in KSW-2-based mesoporous silica through organic modification of as-synthesized KSW-2 and subsequent hydrolysis of organic groups under very mild conditions. It is very important for defining the crystal structure of the KSW-2-based mesoporous silica to discuss further the crystal structures of layered $\mathrm{C}_{16}$ TMA-kanemite complex and as-synthesized KSW-2.

Layered $\mathbf{C}_{16}$ TMA-kanemite complex. After the reaction with $\mathrm{C}_{16} \mathrm{TMACl}$ for 3 days at room temperature $\left(\mathrm{C}_{16} \mathrm{TMA} / \mathrm{Si}=2.0\right)$, a main peak at the $d$-spacing of $2.85 \mathrm{~nm}$ and the higher order reflections (1.42 and $0.94 \mathrm{~nm}$ ) were observed. It is considered that the lattice constant was expanded by the reaction with $\mathrm{C}_{16} \mathrm{TMACl}$ in the $b$ axis and the peaks are assignable to (020), (040), and (060) peaks, respectively. If the orthorhombic structure of kanemite is retained completely even after the reaction (the $b$ axis is just expanded to 5.70 $\mathrm{nm}$ by intercalation of $\mathrm{C}_{16}$ TMA cations), the corresponding peaks must be observed at each position with calculated $d$-spacing ( $a=0.4946 \mathrm{~nm}, b=5.70 \mathrm{~nm}$ and $c=0.7275 \mathrm{~nm}$ ). However, the peak positions did not match with the observed ones. Although the layered nature of kanemite is retained, it is much complicated to index other peaks on the basis of the kanemite structure because the (200) and (301) peaks except for the (002) and (004) peaks were not observed at the same positions as observed for kanemite. 


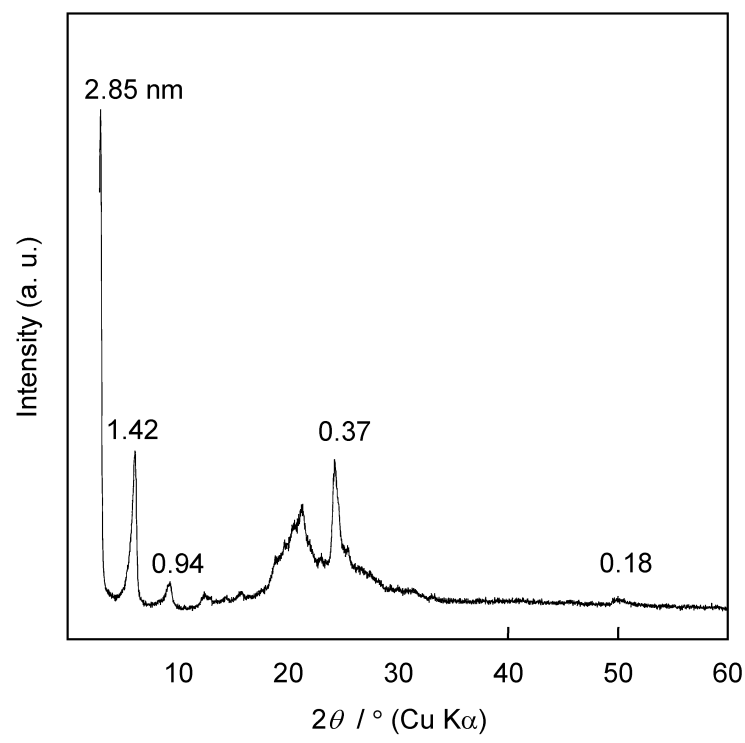

Figure S3. XRD pattern of layered $\mathrm{C}_{16} \mathrm{TMA}$-kanemite complex.

Table S2. XRD result on the synthesis of layered $\mathrm{C}_{16}$ TMA-kanemite complex prepared at room temperature.

\begin{tabular}{|c|c|c|}
\hline Observed & $h k l$ & $\begin{array}{l}\text { Calculated* (If orthorhombic) } \\
a=0.4946 \mathrm{~nm} \\
b=5.70 \mathrm{~nm} \\
c=0.7275 \mathrm{~nm}\end{array}$ \\
\hline 2.85 & 020 & 2.850 \\
\hline 1.42 & 040 & 1.425 \\
\hline 0.94 & 060 & 0.950 \\
\hline 0.70 & 080 & 0.713 \\
\hline 0.67 & & \\
\hline 0.01 & 061 & 0.578 \\
\hline 0.56 & 0100 & 0.570 \\
\hline 0.47 & 0120 & 0.475 \\
\hline 0.45 & 150 & 0.454 \\
\hline 0.43 & & \\
\hline 0.42 & & \\
\hline 0.40 & $\begin{array}{lll}1 & 1 & 1\end{array}$ & 0.408 \\
\hline & 151 & 0.385 \\
\hline 0.37 & 002 & 0.364 \\
\hline & 022 & 0.361 \\
\hline $\begin{array}{l}0.35 \\
0.34\end{array}$ & & \\
\hline & 152 & 0.284 \\
\hline & 200 & 0.247 \\
\hline & 103 & 0.218 \\
\hline
\end{tabular}


All of the $\mathrm{SiO}_{4}$ units are equivalent in the original kanemite, proved by the ${ }^{29} \mathrm{Si}$ MAS NMR spectrum showing only one peak at $-97 \mathrm{ppm}$. Although the $Q^{3}$ environment was almost kept in the layered complex, the peak was split into three or more peaks mainly at -100 and $-103 \mathrm{ppm}$ in addition to the peak at $-97 \mathrm{ppm}$. The variation of the chemical shift is possibly due to the change of $\mathrm{Si}-\mathrm{O}-\mathrm{Si}$ bond angle induced by the change from the interactions of silicate sheets with $\mathrm{Na}^{+}$to those with cationic headgroups in $\mathrm{C}_{16}$ TMA ions. In addition, the kanemite-based structure is retained in the silicate framework of layered complex because the peaks concerning with the $c$ axis are detected by XRD and $Q^{2}$ peak due to fragmentation of the individual silicate sheets in kanemite is hardly observed by ${ }^{29}$ Si MAS NMR. However, we would need to elasticate the silicate sheets of kanemite (the lattice constants are expanded and contracted in the $a$ and $c$ axes) to match with the $\mathrm{XRD}$ result for further structural investigation on the layered complex.

As-synthesized KSW-2. The low-angle XRD pattern of as-synthesized KSW-2 showed peaks $\left(d_{11}=4.05, d_{20}, d_{02}=2.98\right.$, and $\left.d_{22}=1.99 \mathrm{~nm}\right)$ assignable to a 2-D orthorhombic mesostructure $(c 2 \mathrm{~mm})$ with $a=5.96 \mathrm{~nm}$ and $b=5.48 \mathrm{~nm}$. The wide-angle XRD pattern of as-synthesized KSW-2 showed two distinct peaks corresponding to the $d$-spacings of 0.37 and $0.19 \mathrm{~nm}$, which reflects a periodic structure due to the (002) and (004) peaks based on the crystal structure of kanemite. In this case, a peak with the $d$-spacing of $6.7 \mathrm{~nm}$ was also observed. The TEM images and the corresponding SAED patterns of as-synthesized KSW-2 exhibit the presence of regularly arranged 1-D squared mesopores. As in the case of silylated and hydrolyzed KSW-2-based mesoporous silica, slightly arc-shaped spots concerning with $\sim 0.37 \mathrm{~nm}$ were observed perpendicular to the spots of the ordering of mesochannels in the SAED pattern of as-synthesized KSW-2. We concluded from the TEM result that the silicate sheets are bent along the $a$ axis based on the kanemite structure to form as-synthesized KSW-2. We have proposed a reason for the bending of silicate sheets along the $a$ axis on the basis of the distribution of silanol ( $\mathrm{Si}-\mathrm{OH})$ groups. In accordance with the difference between the distribution of $\mathrm{Si}-\mathrm{OH}$ groups along the $a$ (2.02 groups $\mathrm{nm}^{-1}$ ) and $c$ axes (2.75 groups $\mathrm{nm}^{-1}$ ), the interval of headgroups of $\mathrm{C}_{16}$ TMA cations along the $a$ axis is larger than that along the $c$ axis. Therefore, lamellar assemblies of $\mathrm{C}_{16} \mathrm{TMA}$ ions in the layered complex are preferable to increase the lateral distance along the $a$ axis of the layered complex during mild acid treatment by gradually leaching out $\mathrm{C}_{16}$ TMA ions, leading to the transformation into rod-like assemblies in as-synthesized KSW-2 with the bending of silicate sheets along $a$ axis. 

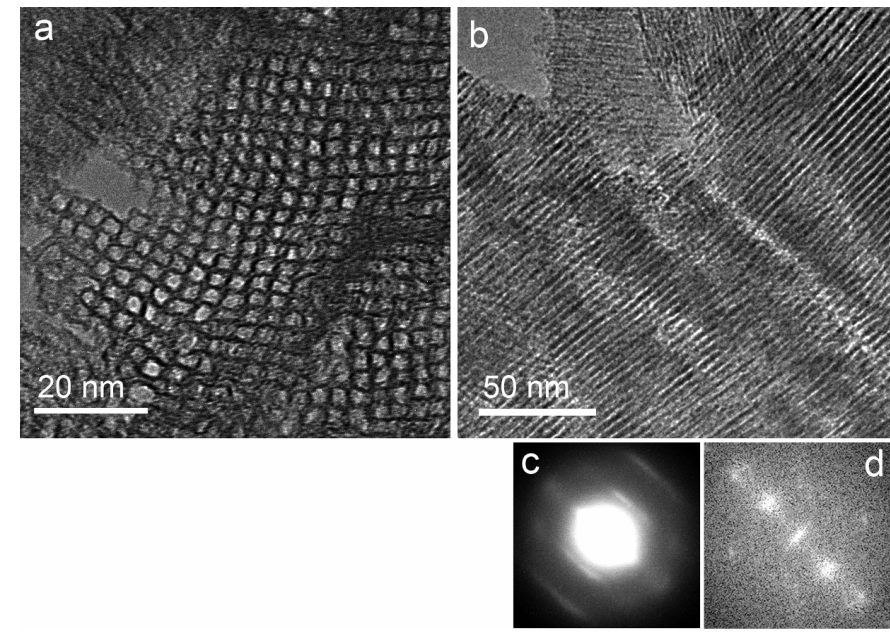

Supporting Figure S4. TEM images taken along with (a) parallel and (b) perpendicular directions to the 1-D mesopore of as-synthesized KSW-2, and (c) the corresponding SAED pattern and (d) the Fourier diffractogram of (b).

S4. $\alpha_{\mathrm{s}}$-plot of $\mathrm{KSW}-2$ silylated with $\mathrm{C}_{8} \mathrm{H}_{17} \mathrm{OSiCl}_{3}$ and hydrolyzed.

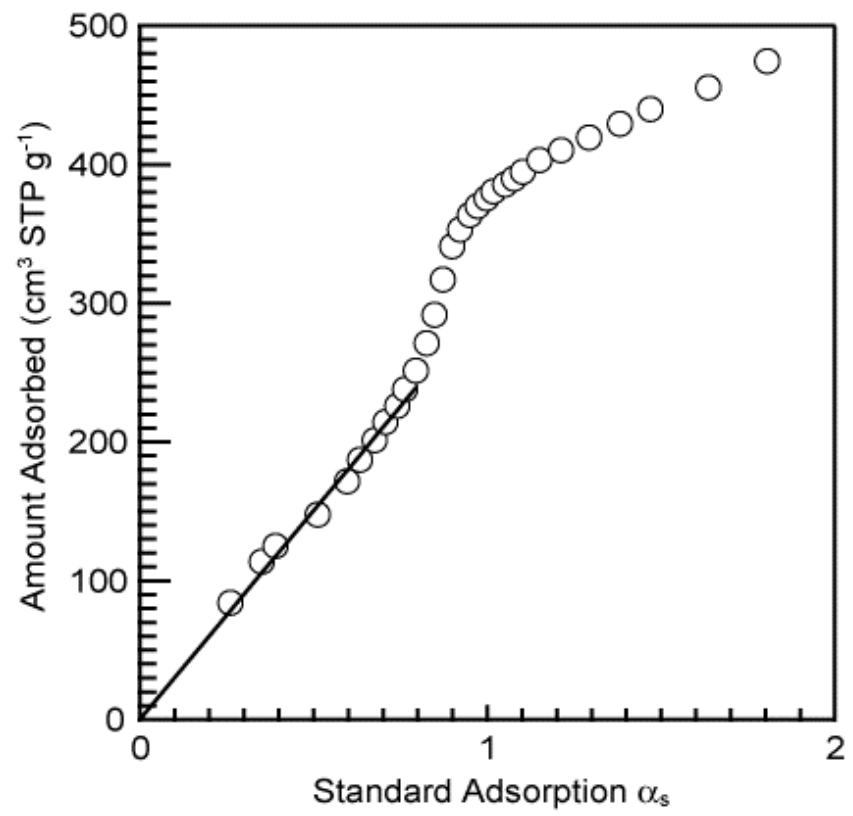

Supporting Figure S5. $\alpha_{\mathrm{s}}$-plot of $\mathrm{KSW}-2$ silylated with $\mathrm{C}_{8} \mathrm{H}_{17} \mathrm{OSiCl}_{3}$ and hydrolyzed. 
S5. $\mathrm{N}_{2}$ adsorption-desorption isotherms of the porous products obtained during the silylation using $\mathrm{C}_{8} \mathrm{H}_{17} \mathrm{OSiCl}_{3}$

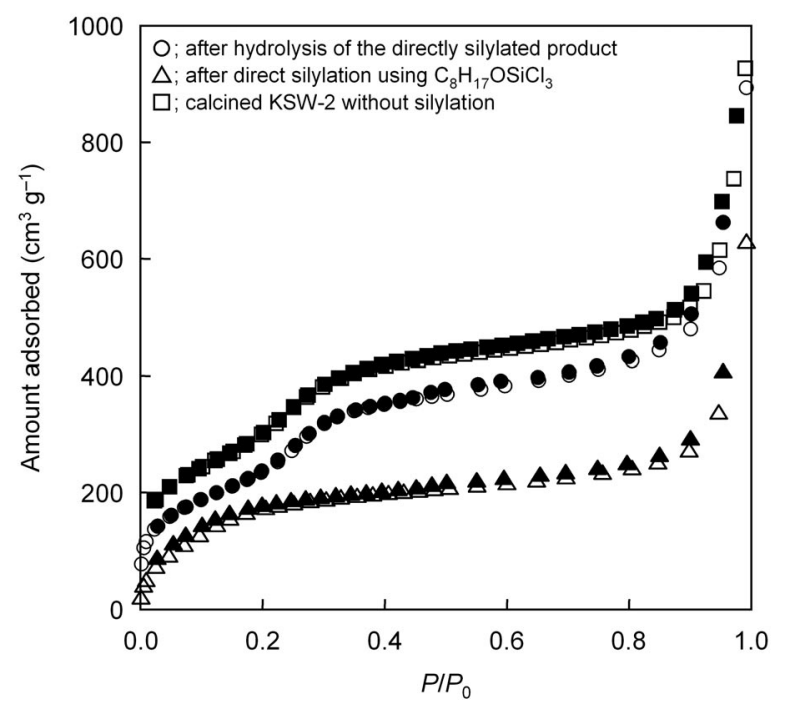

Supporting Figure S6. $\mathrm{N}_{2}$ adsorption-desorption isotherm of calcined KSW-2 without silylation, KSW-2 silylated with $\mathrm{C}_{8} \mathrm{H}_{17} \mathrm{OSiCl}_{3}$, and the hydrolyzed product. Filled symbols denote desorption.

S6. ${ }^{29} \mathrm{Si}$ MAS NMR of KSW-2 silylated with $\mathrm{C}_{8} \mathrm{H}_{17}\left(\mathrm{CH}_{3}\right) \mathrm{SiCl}_{2}$.

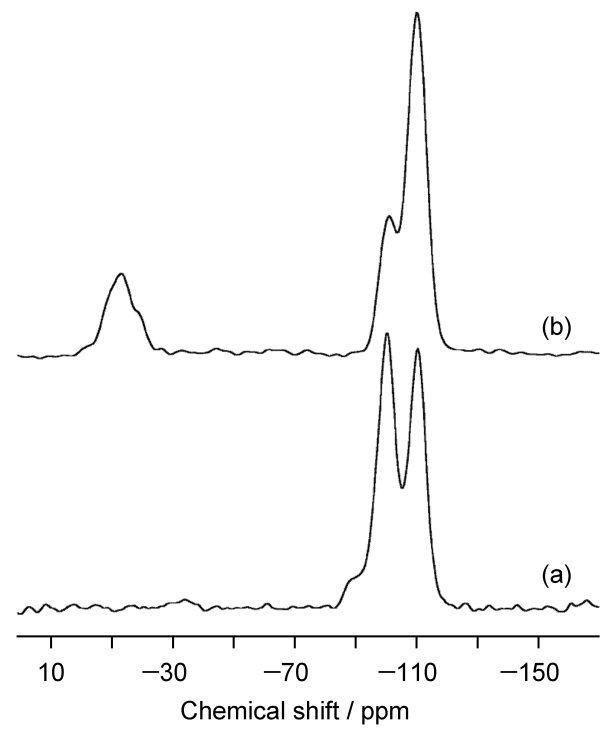

Supporting Figure S7. ${ }^{29} \mathrm{Si}$ MAS NMR spectra of (a) as-synthesized KSW-2 and (b) KSW-2 silylated with $\mathrm{C}_{8} \mathrm{H}_{17}\left(\mathrm{CH}_{3}\right) \mathrm{SiCl}_{2}$. 
S7. $\mathrm{N}_{2}$ adsorption-desorption isotherms of the porous products obtained during the silylation using $\mathrm{C}_{8} \mathrm{H}_{17}\left(\mathrm{CH}_{3}\right) \mathrm{SiCl}_{2}$

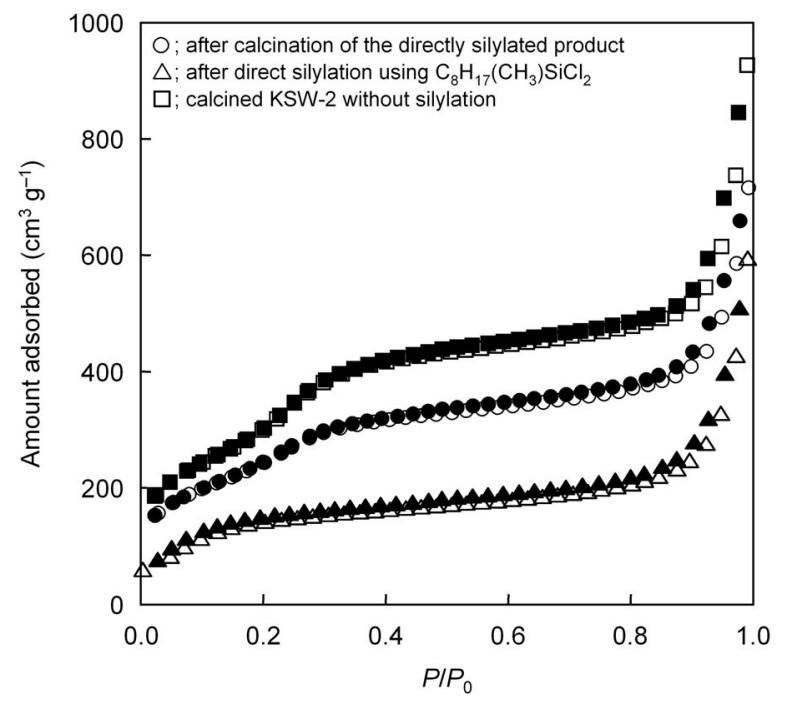

Supporting Figure S8. $\mathrm{N}_{2}$ adsorption-desorption isotherms of calcined KSW-2 without silylation, KSW-2 silylated with $\mathrm{C}_{8} \mathrm{H}_{17}\left(\mathrm{CH}_{3}\right) \mathrm{SiCl}_{2}$, and the calcined material. Filled symbols denote desorption. 